\title{
Lithium Ion Battery Fire and Explosion
}

\author{
QINGSONG WANG, JINHUA SUN, and GUANQUAN CHU \\ State Key Laboratory of Fire Science \\ University of Science and Technology of China \\ Hefei 230026, P.R. China
}

\begin{abstract}
With the extensive applications of lithium ion batteries, many batteries fire and explosion accidents were reported. Base on the combustion triangle theory, the combustion triangle contributions of lithium ion battery were analysed. By using C80 micro calorimeter, the thermal behavior studies on the materials show that the flammable electrolyte, oxygen generated by charged cathode and anode decomposition, and exothermic reaction heats form the combustion triangle together. The thermal runaway of working materials in lithium ion battery system was studied with common used battery materials, and the no return temperature $T_{N R}$ was calculated is $75^{\circ} \mathrm{C}$ and the self-accelerating decomposition temperature (SADT) is $66.5^{\circ} \mathrm{C}$. Further analysis shows that the lithium ion battery reaction chain according with Domino effect, therefore, the lithium ion battery fire and explosion developing sequences was drawn by Domino chain. The Domino chain explains the fire and explosion developing process perfectively, and then the countermeasures can be taken by breaking the Domino chain for the safety of lithium ion battery.
\end{abstract}

KEYWORDS: lithium ion battery, explosion, fire, combustion triangle, thermal runaway, domino effect

\section{INTRODUCTION}

In 1991, Sony commercialized the Lithium ion battery and it is extensively used in many fields at present [1], such as many kinds of portable electronic equipments and electric vehicle or hybrid electric vehicle. When lithium ion batteries replaced nickel metal hydride, researchers increased the energy density, eliminated the memory effect, and made batteries lighter. But despite those merits gain, there is one big drawback: lithium ion batteries are flammable. Lithium ion batteries in most cases use cobalt oxide, which has a tendency to undergo "thermal runaway". When the material is heated up, it can reach an onset temperature that begins to self-heat and progresses into fire and explosion. The organic electrolytes in many lithium ion batteries are highly flammable when heated.

A bulletin from Island Tel of Prince Edward Island reported two cases of Cellular Phone Batteries being shorted out and causing a fire hazard. It also was reported that two researchers were hurt by lithium ion battery explosion in November 11, 2004 Shanghai, as well as many cases were reported before.

The safety problem of lithium ion batteries have become one key handicap in theirs popularization, many researches have been carried out in the thermal decomposition of electrolyte, anode and cathode [2-4]. However, the fire and explosion theory of lithium ion battery is few reported and needed further studies to ensure the safe use of lithium ion batteries. 


\section{FIRE AND EXPLOSION THEORY OF LITHIUM ION BATTERY}

\section{Combustion Triangle}

Fire is a process involving rapid oxidation at elevated temperatures accompanied by the evolution of heated gaseous products of combustion, and the emission of visible and invisible radiation. The combustion process is usually associated with the oxidation of a fuel in the presence of oxygen with the emission of heat and light. Three components are necessary for combustion to occur: fuel, oxygen and an ignition source. It is the well known as the combustion triangle, which can be shown as Fig. 1. Recognizing these components and controlling their interaction is critical to safety.

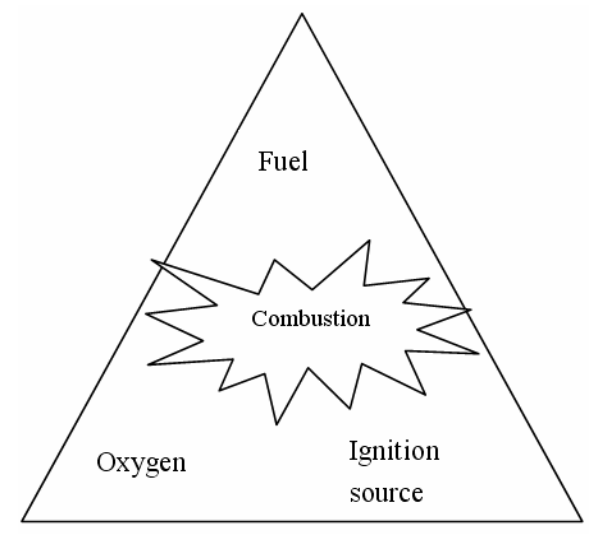

Fig. 1. Combustion triangle.

The first component of the combustion triangle is fuel. There must be sufficient fuel present in the air to form an ignitable mixture. The fuel may be in the form of a gas, vapor, mist or dust. The second component of the combustion triangle is oxygen. For combustion to occur oxygen is necessary only at normal concentrations present in the air we breathe. The ignition sources are perhaps the most variable and unpredictable. For electrical equipment this may be from an arcing or sparking device or from a hot surface. There may be sources of ignition other than electrical equipment, such as hot exhaust surfaces from internal combustion engines.

Essentially all three elements must be present for fire to occur. Removal of fuel or oxygen will result in the fire being extinguished, if the fire itself is considered as a source of ignition, then, the removal of ignition source also will result in the fire being extinguished. Further fire research determined that a fourth element, a chemical chain reaction, was a necessary component of fire. The fire triangle was changed to a fire tetrahedron to reflect this fourth element. Here, the combustion triangle theory was used to explain the battery fire and explosion.

\section{Contributions of Three Components in Lithium Ion Battery}

The three components are also necessary for combustion or burning in lithium ion battery. The main fuel in lithium ion battery is electrolyte, which is a solution consists of organic solvent and inorganic salt. The most common solvents used in lithium ion batteries are the ethylene carbonate (EC), propylene carbonate (PC), dimethyl carbonate (DMC), and diethyl carbonate (DEC), and combinations thereof. Lithium 
hexafluorophosphate $\left(\mathrm{LiPF}_{6}\right)$ is by far the most widely used electrolyte salt in lithium ion batteries. However, their thermal stability is poor even at moderately elevated temperatures of $60-85^{\circ} \mathrm{C}$. The salt is believed to play the role of a mediator in the solution's decomposition [5]. Such flammable materials are the fuels and easy ignited in air, once the batteries is blasted to fragment, then, there has the danger of fire under the effect of explosion energy.

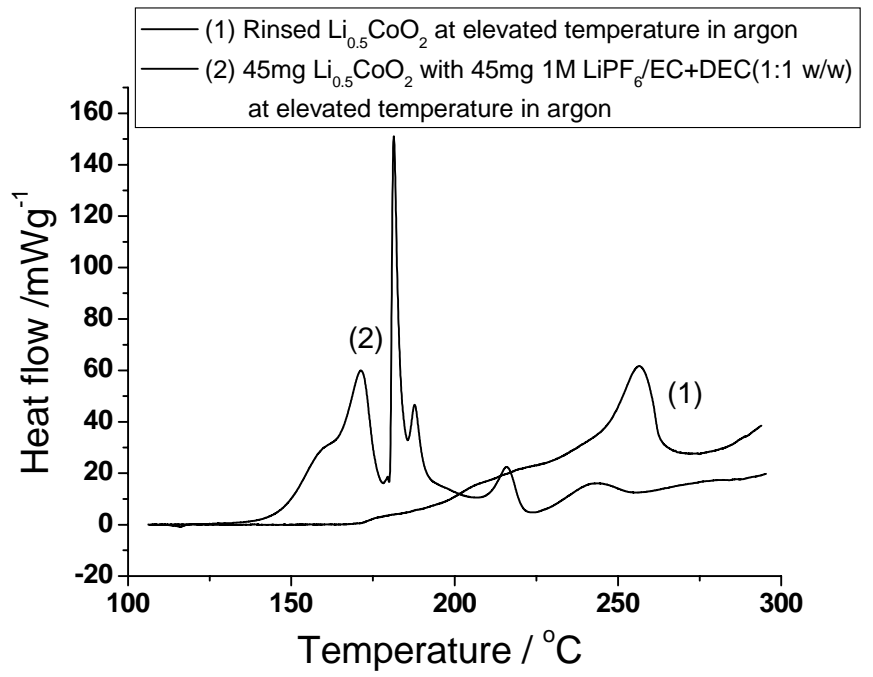

Fig. 2. The $\mathrm{Li}_{0.5} \mathrm{CoO}_{2}$ thermal behavior at elevated temperature. Heating rate: $0.2^{\circ} \mathrm{C} \cdot \mathrm{min}^{-1}$.

The lithium ion battery is a closed system and was separated from air, so in normal using there is no explosion or fire dangerous, but the abusing of lithium ion battery will generate the danger of thermal runaway. The charged positive electrode is an unstable material, it was studied at elevated temperature, and Fig. 2 shows the thermal behavior of $\mathrm{Li}_{0.5} \mathrm{CoO}_{2}$ in argon atmosphere. The battery was charged to $4.2 \mathrm{~V}$, and then the delithiated $\mathrm{LiCoO}_{2}$, i.e., $\mathrm{Li}_{0.5} \mathrm{CoO}_{2}$, was taken from the battery, and rinsed with DMC twice. The heat flow curve shows stable thermal behavior before $170^{\circ} \mathrm{C}$, while with the addition of electrolyte, it is less stable, and the onset temperature is $130^{\circ} \mathrm{C}$. MacNeil $[6,7]$ reported that the delithiated $\mathrm{Li}_{0.5} \mathrm{CoO}_{2}$ decomposes over $200^{\circ} \mathrm{C}$ and release $\mathrm{O}_{2}$ as Eq. 1:

$\mathrm{Li}_{0.5} \mathrm{CoO}_{2} \rightarrow \frac{1}{2} \mathrm{LiCoO}_{2}+\frac{1}{6} \mathrm{Co}_{3} \mathrm{O}_{4}+\frac{1}{6} \mathrm{O}_{2}$

With the presence of solvent at elevated temperature, $\mathrm{Co}_{3} \mathrm{O}_{4}$ is an intermediate and could decompose to $\mathrm{CoO}$ and $\mathrm{O}_{2}$ as following Eq. 2:

$\mathrm{Co}_{3} \mathrm{O}_{4} \rightarrow 3 \mathrm{CoO}+\frac{1}{2} \mathrm{O}_{2}$ 
The generated oxygen is one of the contributions to combustion triangle, at the same time, the negative electrode also releases oxygen and contribute to the combustion triangle. Fig. 3 shows the thermal behavior of charged negative electrode at elevated temperature. The heat flow profile shows that there are four exothermic peaks, and the first exothermic process is small and the mechanism needs further research. The second exothermic is thought the solid electrolyte interface (SEI) decomposing process, which is formed by stable layer, e.g., $\mathrm{Li}_{2} \mathrm{CO}_{3}$, and sub-stable layer, e.g., $\left(\mathrm{CH}_{2} \mathrm{OCO}_{2} \mathrm{Li}\right)_{2}$. The decomposition reaction onset temperature is $74^{\circ} \mathrm{C}$, it reached to peak at $84^{\circ} \mathrm{C}$, and the reaction as Eq. 3 [2]:

$\left(\mathrm{CH}_{2} \mathrm{OCO}_{2} \mathrm{Li}\right)_{2} \rightarrow \mathrm{Li}_{2} \mathrm{CO}_{3}+\mathrm{C}_{2} \mathrm{H}_{4}+\mathrm{CO}_{2}+\frac{1}{2} \mathrm{O}_{2}$

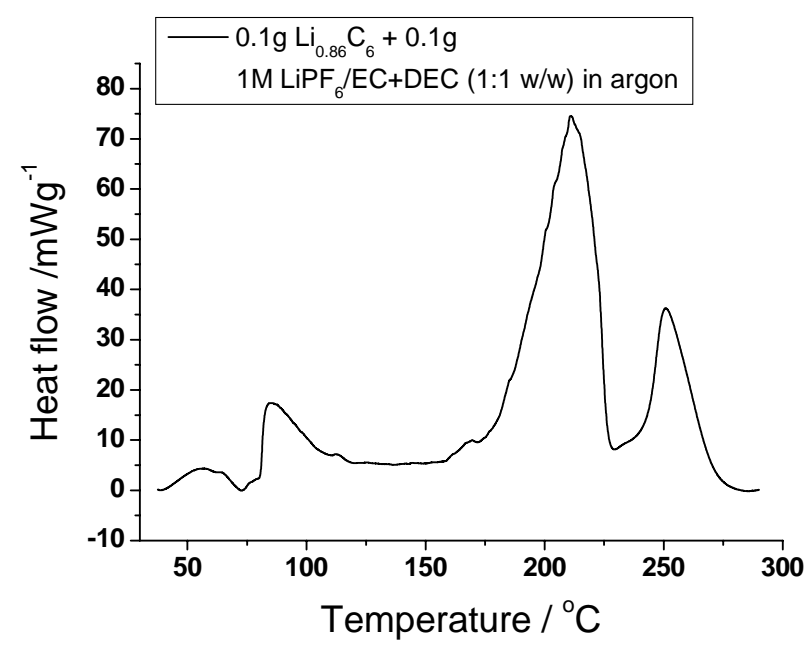

Fig. 3. The $\mathrm{Li}_{0.86} \mathrm{C}_{6}$ with electrolyte thermal behavior at elevated temperature. Heating rate: $0.2^{\circ} \mathrm{C} \cdot \mathrm{min}^{-1}$.

The same with $\mathrm{Li}_{0.5} \mathrm{CoO}_{2}$ decomposition, the generated $\mathrm{O}_{2}$ are the contributions for both the combustion triangle and the rising up pressure in the lithium ion battery.

Both the cathode and anode decomposition are the exothermic processes, and the generated heats act as the necessary energy of the consequent reactions, which form the reaction chain, and more reactions with more heat output. By integrating the heat flow curves, the total reactions release $920 \mathrm{~J} \cdot \mathrm{g}^{-1}$ and $1,870 \mathrm{~J} \cdot \mathrm{g}^{-1}$ heats without/with electrolyte in Fig. 2, respectively, and the $\mathrm{Li}_{0.86} \mathrm{C}_{6}$ with electrolyte is $470 \mathrm{~J} \cdot \mathrm{g}^{-1}$ in Fig. 3. If heat transfer from the cell materials to the surrounding is neglected, and all the energy effect on the battery, that is act as the ignition source, then the battery is undergoing the danger of fire and explosion.

\section{Thermal Diagraph of Lithium Ion Battery}

The fuel, oxygen and energy provide the probability of fire and explosion, as the lithium ion battery is a closed system, so the gas products cause the increasing of the inner 
pressure and the exothermic heats heat up the system. With the rising up of the battery temperature, more chemical reactions occur, and more heat generation. Once the heat generation is greater than the heat loss, the battery system will undergo 'temperature of no return', then the thermal runaway. The heat generation is decided by the materials, and the heat loss decided by the battery can. The latter is changing with the ambient temperature and other related considerations. An elegant way to visualize thermal runway reactions is in the plots often referred to as Semenov plots [8] in Fig. 4. The curved line, 4 , represents the heat generation due to an exothermic reaction (exponential function, assuming Arrhenius law) while the straight lines represent the heat removal which is a linear function (Newton's law of cooling) at different coolant temperatures. The temperature of the coolant can be sufficiently low (case of line 1) or insufficiently, like in case 3 where thermal control is not possible under any circumstances. Line 1 has two points of intersection with line 4. Isothermal operation is possible in both points. The lower point $\mathrm{E}$ of intersection is a stable point. If temperature deviates upwards cooling power is higher than power generated by the reaction thus the system will return to the temperature of the stable point of operation. If temperature drops, as power generation is higher than power removal temperature will again return to that point. The second (higher point $\mathrm{F}$ of intersection), however, is an unstable one. If temperature drops it will carry on dropping until it reaches the stable point, as power removal is higher than power generation, but if it deviates upwards the runaway is inevitable. Line 2 has one tangent point $\mathrm{D}$ with line 4 , this point is a critical point, as power removal is equals to power generation, and thus, this critical equilibrium temperature is called the 'Temperature of No Return'. The temperature B is called the self-accelerating decomposition temperature (SADT).

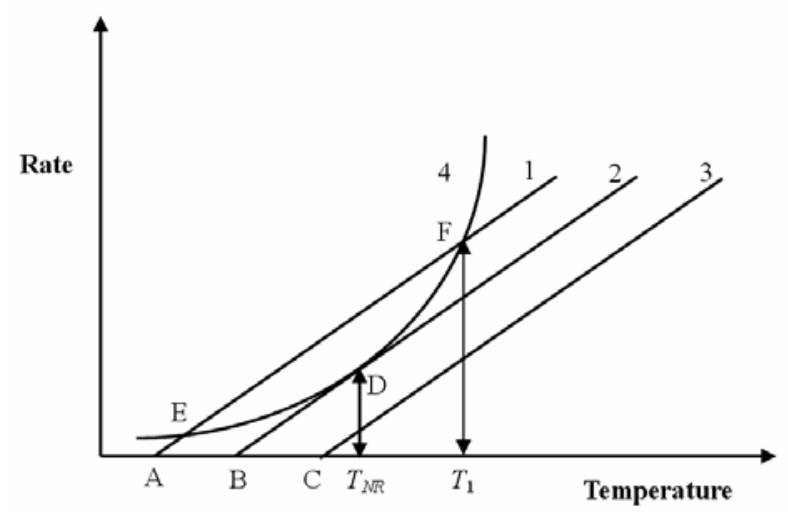

Fig. 4. Thermal diagraph of a reaction and heat loss from a vessel, at 3 ambient temperatures, A, B, and C. A can control the sample to temperature $T_{1}, \mathrm{~B}$ is at the critical temperature $T_{N R}$ and $\mathrm{C}$ cannot control the thermal runaway.

In lithium ion battery, a charged $(4.2$ V) 2032 battery was tested by C80 micro calorimeter at elevated temperature. The charged battery was disassembled, and the total reactive mass of the battery working materials is $178 \mathrm{mg}$, which consist of $106 \mathrm{mg} 1 \mathrm{M}$ $\mathrm{LiPF}_{6}$ in EC+DEC (1:1 w/w) electrolyte, $34 \mathrm{mg}$ delithiated $\mathrm{Li}_{0.5} \mathrm{CoO}_{2}, 35 \mathrm{mg}$ intercalated $\mathrm{Li}_{0.86} \mathrm{C}_{6}$, and $2.5 \mathrm{mg}$ separator. The whole heat flow of the battery reactive materials was shown in Fig. 5. By integrating the elevated heat flow curve of the battery, the reaction heats $\Delta H$ can be easily calculated as $\Delta H=1036 \mathrm{~J}^{-1}$. Based on the Arrhenius law, and assuming the reaction order is one, the pre-exponential factor $(A)$ and activation 
energy ( $E$ ) can be calculated [9]. The calculated result $A=2.41 \times 10^{11} \mathrm{~s}^{-1}, E=118 \mathrm{~kJ} \cdot \mathrm{mol}^{-1}$. As the mixed materials react with each others, then, the mixture is similar with one self reactive substance. According to the Semenov model [10], the no return temperature $\left(T_{N R}\right.$ ), and the SADT of the $25 \mathrm{~kg}$ standard package (the package: wet area $S=4812.4 \mathrm{~cm}^{2}$, overall heat transfer coefficient $U=2.8386 \mathrm{~J} \cdot \mathrm{m}^{-2} \cdot \mathrm{K}^{-1} \cdot \mathrm{s}^{-1}$ ) of the battery mixed materials is calculated, and the value $T_{N R}=75^{\circ} \mathrm{C}$, and the SADT $=66.5^{\circ} \mathrm{C}$. The result indicates that if the temperature of lithium ion battery materials is over $66.5^{\circ} \mathrm{C}$, the charged battery will undergo self-heating, and if the temperature is exceed $75^{\circ} \mathrm{C}$, it will undergo thermal runaway. From Arrhenius equation it becomes obvious that the decomposition "onset" is not a "fixed" temperature, the lower the heating rate employed in experimental tests the lower the decomposition "onset" found. Furthermore, as the reliability of predictions are obtained from very small samples. Therefore, for larger batteries, such as lithium ion 18650 batteries, it can be speculated that although temperatures higher than $75^{\circ} \mathrm{C}$ will certainly result in a thermal runaway, temperatures lower than $75^{\circ} \mathrm{C}$ can provoke the runaway as well. As to other kind of materials of batteries, similar method can be taken to evaluate theirs thermal behaviors.

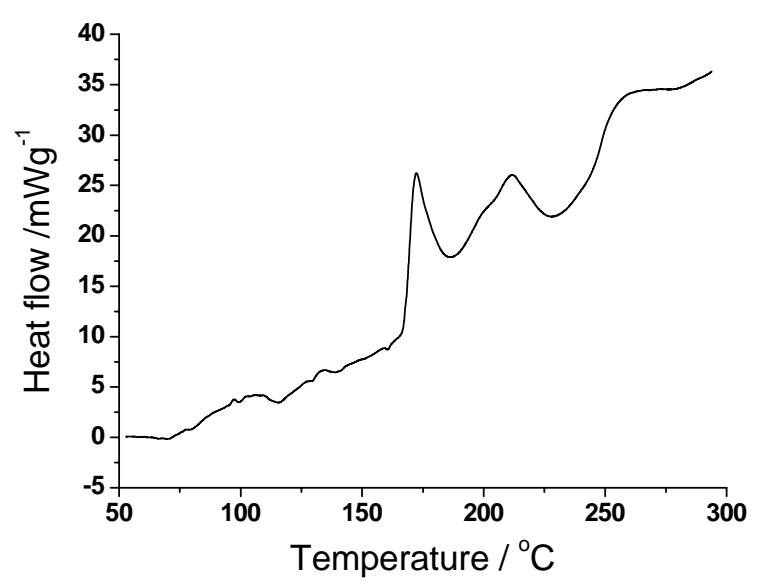

Fig. 5. Heat flow profile of lithium ion battery at elevated temperature. Heating rate: $0.2^{\circ} \mathrm{C} \cdot \mathrm{min}^{-1}$.

\section{Fire and Explosion Accident Chain of Lithium Ion Battery}

If the battery is undergoing thermal runaway reactions, then, the explosion or fire is inescapable. In normal using of the battery, the temperature is below $40^{\circ} \mathrm{C}$, which is lower, but the abusing, such as short circuit, overcharge, apply reverse polarity or expose to high temperature, will cause the temperature rising up quickly. When the temperature is exceed $66.5^{\circ} \mathrm{C}$, more reactions occur and generate more heat to quicken up self heating reaction. Thereafter, if the temperature is over $75^{\circ} \mathrm{C}$, then the reaction will without return. With more chain reactions undergoing, gas and heat are cumulated, once the inner pressure exceed the battery endurance, the explosion is inescapable, and the fragments is easy be ignited and to cause fire. The whole process can be shown as following Fig. 6 . The accident can be described as the Domino effect [11], which is defined as those situations where an accident becomes the initiating event of one or more other accidents, 
thus, increasing the severity of the off-site consequences. If one of the Domino events is moved from the chain, then the e fire and explosion can be avoided, so the relative countermeasures can be taken to move or avoid the occurrence of the chain event, e.g., in order to decrease the battery temperature, the good thermal conductive materials can be designed as battery shell. As to the energy and gas cumulation, a safety valve should be designed in the battery and can open automatically when the inner pressure exceed the certain level, by this way, to ensure the battery safety.

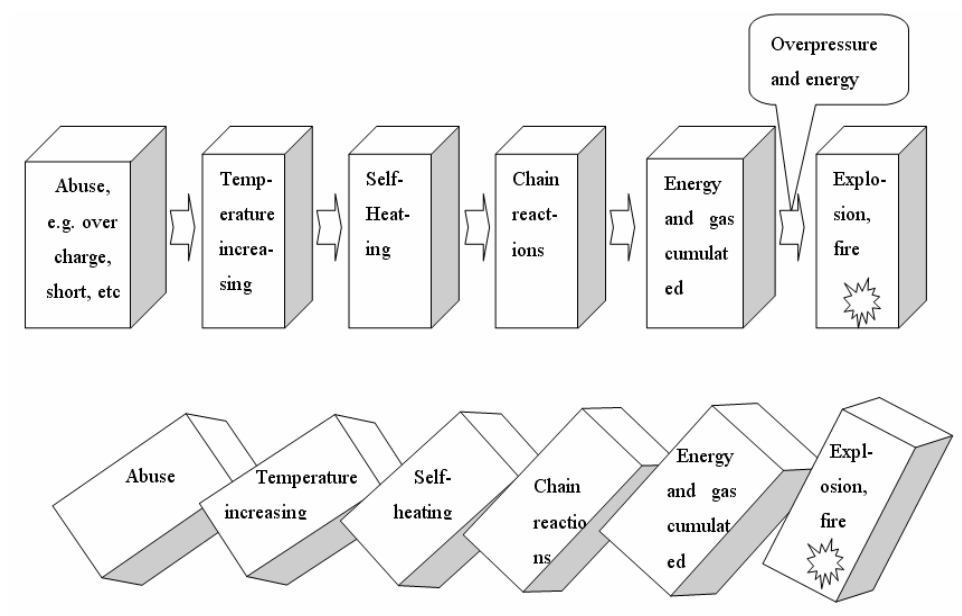

Fig. 6. Domino effect of lithium ion battery fire and explosion.

Crush, mutilate, nail penetrate or disassemble will damaged the battery fatally, the consequence is more dangerous. The above abuses are easy cause to the short circuit and then bring to the Domino effect, and furthermore, the flammable electrolyte exposed to air is dangerous hazard too.

\section{CONCLUSIONS}

Lithium ion batteries have a very high energy density and have wide applications. While the flammable, high energy and active material increase their dangers of fire and explosion. The fuel, oxygen and energy can exist in the battery system, which provide the necessary contributions to the combustion triangle, thus there is the possibility of fire and explosion. The $\mathrm{Li}_{0.5} \mathrm{CoO}_{2}$ positive electrode and $\mathrm{Li}_{0.86} \mathrm{C}_{6}$ negative electrode decompose with the temperature rising up, at $170^{\circ} \mathrm{C}$ and $74^{\circ} \mathrm{C}$ respectively. The reaction oxygen products and large mount of exothermic heat are contributed to the combustion triangle.

The charged lithium ion battery materials are reactive substance with high activity, based on Semenov theory, the lithium ion battery materials will undergo the thermal runaway process at elevated temperature, and the SADT is $66.5^{\circ} \mathrm{C}$, and no return temperature $T_{N R}$ is $75^{\circ} \mathrm{C}$ for the $(-) \mathrm{C}\left|\mathrm{LiPF}_{6}-\mathrm{EC}+\mathrm{DEC}\right| \mathrm{LiCoO}_{2}(+)$ battery. For larger lithium ion batteries, both SADT and $T_{N R}$ should be lower.

In the thermal runaway process, a large mount of reaction occur and form the reaction chain till to fire and explosion, which illuminates the Domino effect. Then, measures can be taken to break the Domino chain to prevent the accident, such as safety valve. 
Furthermore, just one single small battery is studied in this paper, while a pile is used for higher power volt in many cases, which will bring more new questions, e.g., if a fire or explosion in one battery can set off an explosive chain reaction in the other batteries in a module? It is obvious that when one phone battery blows up, it's not such a big deal, but with a hybrid battery, a ton of energy was generated, which no longer a small deal. All of that are need further researches.

\section{ACKNOWLEDGEMENTS}

This study was supported by ' 100 Talents Project' of Chinese Academy of Sciences and China NKBRSF project, No. 2001CB409600.

\section{REFERENCES}

[1] Wakihara, M., "Recent Developments in Lithium Ion Batteries," Materials Science and Engineering, R33, pp. 109-134, (2001).

[2] Kawamura, T., Kimura, A., Egashira, M., Okada, S., and Yamaki, J.I., "Thermal Stability of Alkyl Carbonate Mixed-solvent Electrolytes for Lithium Ion Cells,” Journal of Power Sources, 104, pp. 260-264, (2002).

[3] Jiang, J.W., and Dahn, J.R., "Effects of Solvents and Salts on the Thermal Stability of LiC $_{6}$," Electrochimica Acta, 49, pp. 4599-4604, (2004).

[4] Baba, Y., Okada, S., Yamaki, J., "Thermal Stability of $\mathrm{Li}_{\mathrm{x}} \mathrm{CoO}_{2}$ Cathode for Lithium Ion Battery,” Solid State Ionics, 148, pp. 311-316, (2002).

[5] Ravdel, B., Abraham, K.M., Gitzendanner, R., DiCarlo, J., Lucht, B., and Campion, C., "Thermal Stability of Lithium-ion Battery Electrolytes," Journal of Power Sources, 119-121, pp. 805-810, (2003).

[6] MacNeil, D.D., and Dahn, J.R., "The Reactions of $\mathrm{Li}_{0.5} \mathrm{CoO}_{2}$ with Nonaqueous Solvents at Elevated Temperatures," Journal of The Electrochemical Society, 149, (7), pp. A912-A919, (2002).

[7] MacNeil, D.D., and Dahn, J.R., "The Reaction of Charged Cathodes with Nonaqueous Solvents and Electrolytes I. $\mathrm{Li}_{0.5} \mathrm{CoO}_{2}$, , Journal of The Electrochemical Society, 148, (11), pp. A1205-A1210, (2001).

[8] Semenov, N.N., Some Problems in Chemical Kinetics and Reactivity, Princeton University Press, 1959, Vol. 2, Chap. 8.

[9] Sun, J.H., Li, Y.F., Hasegawa, K., “A Study of Self-accelerating Decomposition Temperature (SADT) Using Reaction Calorimetry,” Journal of Loss Prevention in the Process Industries, 14, pp. 331-336, (2001).

[10] Yu, Y.H., and Hasegawa, K., "Derivation of the Self-accelerating Decomposition Temperature for Self-reactive Substances Using Isothermal Calorimetry,” Journal of Hazardous Materials, 45, pp. 193-205, (1996).

[11] Kourniotis, S.P., Kiranoudis, C.T., Markatos, N.C., "Statistical Analysis of Domino Chemical Accidents," Journal of Hazardous Materials, 71, pp. 239252, (2000). 